\title{
Early weight loss outcomes and glucose metabolism parameters after banded versus non-banded one anastomosis gastric bypass: a prospective randomized trial
}

\author{
Everton CAZZO, Felipe Gilberto VALERINI, Fábio Henrique Mendonça CHAIM, \\ Pedro França da Costa SOARES, Almino Cardoso RAMOS and Elinton Adami CHAIM
}

ABSTRACT - Background - The influence of the placement of a band on the outcomes of one anastomosis gastric bypass (OAGB) has not been appropriately studied yet. Objective - To compare early weight loss and glucose metabolism parameters following banded versus non-banded OAGB. Methods - A prospective randomized study, which evaluated 20 morbidly obese individuals who underwent banded and non-banded OAGB and were followed-up for three months. Weight loss (percentage of excess weight loss - \%EWL and percentage of body mass index loss - \%BMIL) and glucose metabolism outcomes (glucose, insulin and homeostasis model assessment - HOMA) were compared. Results - The banded group presented a significantly higher $\%$ EWL at one month $(29.6 \pm 5.5 \%$ vs $17.2 \pm 3.4 \% ; P<0.0001)$ and two months post-surgery $(46 \pm 7 \%$ vs $34.2 \pm 9 \% ; P=0.004544)$, as well as a significantly higher $\%$ BMIL at one month $(9.7 \pm 1.1 \%$ vs $5.8 \pm 0.8 \% ; P<0.0001)$, two months $(15 \pm 1.4 \%$ vs $11.5 \pm 2.1 ; P=0.000248)$, and three months $(18.8 \pm 1.8 \%$ vs $15.7 \pm 3.2 \% ; P=0.016637)$. At three months, banded OAGB led to significant decreases of insulin $(14.4 \pm 4.3$ vs $7.6 \pm 1.9 ; P=0.00044)$ and HOMA $(3.1 \pm 1.1$ vs $1.5 \pm 0.4 ; P=0.00044)$, whereas non-banded OAGB also led to significant decreases of insulin $(14.8 \pm 7.6$ vs $7.8 \pm 3.1 ; P=0.006)$ and HOMA $(3.2 \pm 1.9$ vs $1.6 \pm 0.8 ; P=0.0041)$. The percent variation of HOMA did not significantly differ between banded and non-banded OAGB $(P=0.62414)$; overall, the percent variation of HOMA was not correlated with \%EWL $(P=0.96988)$ or \%BMIL $(P=0.82299)$. Conclusion - Banded OAGB led to a higher early weight loss than the standard technique. Banded and non-banded OAGB led to improvements in insulin resistance regardless of weight loss.

HEADINGS - Bariatric surgery. Gastric bypass. Weight loss. Obesity. Insulin resistance.

\section{INTRODUCTION}

One anastomosis gastric bypass (OAGB) is a surgical modality described and developed over the last decades, characterized by a simplified operative technique and associated with a reduction in operative time and, therefore, potentially lower morbidity and mortality $^{(1)}$. Initially proposed and named mini-gastric bypass by Rutledge in the late 1990s, the main feature of this procedure is the realization of a single anastomosis, i.e. an omega-loop gastrojejunostomy distant from the duodenojejunal angle ${ }^{(2)}$. Despite some initial resistance, caused by the fear of alkaline reflux to the gastric pouch and consequent risk of carcinogenesis, the procedure has gained wider acceptance in the bariatric field, mainly due to its reported weight loss and metabolic outcomes, as well as its safety profile demonstrated in several studies ${ }^{(3-5)}$. In the last International Federation for the Surgery of Obesity and Metabolic Disorders (IFSO) report, it accounts for about $2 \%$ of all procedures performed in the world ${ }^{(6)}$. The current IFSO position states that OAGB is a recognized bariatric/metabolic technique and should not be considered an experimental procedure ${ }^{(7)}$.
The placement of a band around the gastric pouch to increase the restriction of food intake is acknowledged as a possible way to maximize weight loss after RYGB. On the other hand, the incidence of food intolerance appears to be higher among individuals who underwent banded bypass. Nonetheless, the current reported results in the literature are mixed, with a number studies showing a significantly higher weight loss, and others demonstrating no advantages ${ }^{(8,9)}$. The impact of the placement of bands on the outcomes after OAGB remains not completely determined and, to date and according to our knowledge, two studies performed at the same centre and published by Clarke et al. and Sheikh et al. described this possibility; these authors reported significant weight loss and resolution of co-morbidities ${ }^{(10,11)}$. Furthermore, OAGB has been proven to lead to significant metabolic improvement, with strong evidence demonstrating high rates of diabetes resolution and improvement of insulin resistance ${ }^{(12,13)}$. However, the influence of the placement of a band on these outcomes has not been appropriately studied yet.

This study aims to compare the preliminary early outcomes in regards to weight loss and glucose metabolism parameters following banded versus non-banded OAGB. 


\section{METHODS}

\section{Study design}

This is a prospective non-blinded, randomized intervention study, which evaluated 20 non-diabetic individuals with morbid obesity which underwent OAGB at a tertiary university hospital from September 2017 through January 2018 and were followed-up for three months. The outcomes evaluated were: 30 -day morbidity, 30-day mortality, initial weight and body mass index (BMI) at admittance, preoperative (immediately prior to surgery), one, two, and three months following surgery, percentage of excess weight loss $(\% \mathrm{EWL})$ one, two, and three months following surgery, percentage of BMI loss (\%BMIL) one, two, and three months following surgery, glucose, insulin and homeostasis model assessment - insulin resistance (HOMA-IR) before surgery and after three months. HOMA was calculated according to the formula of Matthews ${ }^{(14)}$.

\section{Study population}

Bariatric surgery was indicated according to the National Institutes of Health criteria ${ }^{(15)}$. The inclusion criteria were: 1) body mass index (BMI) greater than or equal to $\left.40 \mathrm{~kg} / \mathrm{m}^{2} ; 2\right)$ BMI greater than or equal to $35 \mathrm{~kg} / \mathrm{m}^{2}$ associated with obesity-related co-morbidities; 3 ) compliance to take part in the study protocol. The exclusion criteria were: 1) vulnerable groups (mentally ill, institutionalized or aged below 18 years old); 2) previous primary bariatric procedures; 3 ) non-compliance to the proposed followup; 4) type 2 diabetes mellitus; 5) use of drugs which interfere in glucose tolerance and/or insulin sensitivity. All individuals who undergo bariatric surgery at this institution take part in a preoperative weight loss program which lasts 4 to 12 weeks and is comprehended by weekly consultations carried out by a multidisciplinary team. Individuals undergo surgery once a minimal $10 \%$ preoperative weight loss is achieved, or since the minimal BMI of $30 \mathrm{~kg} / \mathrm{m}^{2}$ for subjects with obesity-related morbidities or $40 \mathrm{~kg} / \mathrm{m} 2$ for those free of co-morbidities are reached ${ }^{(16)}$. The weight and BMI at admittance were defined as initial weight and BMI, whereas the weight and BMI immediately prior to surgery were defined as preoperative weight and BMI.

\section{Surgical procedures}

All procedures were laparoscopically performed by the same surgical team led by one of the authors of this study following a previously described technique ${ }^{(17)}$. The main features were: a vertical gastric pouch of about $15-18 \mathrm{~cm}(50-150 \mathrm{~mL})$ and an omega-loop isoperistaltic antecolic stapler side-to-side $3-\mathrm{cm}$ gastrojejunostomy performed $200 \mathrm{~cm}$ further from the Treitz ligament (biliopancreatic limb), with or without the placement of a $6.5-\mathrm{cm}$ silicone ring around the gastric pouch. The band was placed at the middle point in between the gastrojejunostomy and the esophagogastric junction.

\section{Postoperative protocol}

All individuals which undergo surgery remain in a fasting state for 48 hours. Then, an oral methylene blue challenge and a contrast upper radiograph series are performed. Whether there is no evidence of leaks, oral liquid diet is initiated and the individuals are discharged on postoperative day 03. After postoperative day 14 , pasty food is introduced and, when it is appropriately tolerated, solid food is introduced after postoperative day 21 .

\section{Randomization}

Each surgical day, four individuals underwent surgery. They were randomly assessed either for band placement or not the day immediately prior to surgery. The randomization process was electronically performed by means of the Research Randomizer site (http://www.randomizer.org). The individuals were informed of the randomization result and were free to drop out of the study protocol at any time whether there were any discordance.

\section{Compliance to ethical standards}

This study underwent evaluation and was approved by the local Ethics Research Board under the reference 1.957.057/ Unicamp (CAAE: 61556216.2.0000.5404). It was registered at <http:// www.ensaiosclinicos.gov.br> under the reference RBR-59k78k (Universal Trial no. U1111-1203-0901). All individuals provided informed consent.

\section{Statistical analysis}

The baseline characteristics of patients are described and then compared between the groups according to the defined time points. In the univariate analysis of categorical variables, chi-square and Fisher's exact tests were carried out. For the comparison of the continuous variables obtained in the groups, the Mann-Whitney test was used. For correlating non-parametric continuous variables, the Spearman test was used. For the execution of the analysis, it was used Statistic Analysis System (SAS) software for Windows version 9.2

\section{RESULTS}

There were 20 individuals who took part in the study and were divided into two groups of 10 according to band placement or not; there were no significant differences between the groups in regards to gender, age, initial weight and BMI, preoperative weight and BMI, preoperative glucose, insulin, and HOMA-IR. (TABLE 1).

The overall 30-day morbidity was $5 \%$ (one case of trocar site infection); there were no leaks or other major morbidity and the 30-day mortality was nil. No procedure needed to be converted to an open approach. There was no band-related morbidity in the banded group. There were two $(20 \%)$ individuals in each group that complained of vomiting in the second month and two $(20 \%)$ individuals in the banded group and one (10\%) in the non-banded group which presented such complaint in the third month. All of these individuals presented a significant improvement with simple anti-emetic medications and did not require hospital re-internment.

Both groups presented significant weight loss. The mean BMI of the non-banded group significantly decreased from $38.1 \pm 2.3$ $\mathrm{kg} / \mathrm{m}^{2}$ at surgery to $32.2 \pm 2.8 \mathrm{~kg} / \mathrm{m}^{2}$ three months post surgery $(P<0.0001)$; the mean $\%$ EWL at three months was $47.1 \pm 14.1 \%$ and the $\%$ BMIL at three months was $15.7 \pm 3.2 \%$. In the banded group, the mean BMI decreased from $37.6 \pm 2.6 \mathrm{~kg} / \mathrm{m} 2$ to $30.5 \pm 2$ $\mathrm{kg} / \mathrm{m}^{2}(P<0.0001)$; the mean $\%$ EWL at three months was $57.3 \pm 8 \%$ and the $\%$ BMIL at three months was $18.8 \pm 1.8 \%$.

In comparison with the non-banded individuals, the banded group presented significantly higher $\% \mathrm{EWL}$ at one month $(29.6 \pm 5.5 \%$ vs $17.2 \pm 3.4 \% ; P<0.0001)$ and two months post surgery (46 $\pm 7 \%$ vs $34.2 \pm 9 \% ; P=0.004544)$, as well as significantly higher $\%$ BMIL at one month $(9.7 \pm 1.1 \%$ vs $5.8 \pm 0.8 \% ; P<0.0001)$, two months $(15 \pm 1.4 \%$ vs $11.5 \pm 2.1 ; P=0.000248)$, and three months $(18.8 \pm 1.8 \%$ vs $15.7 \pm 3.2 \% ; P=0.016637)$. The complete data is 
TABLE 1. Demographic and anthropometric characteristics, weight loss outcomes, and glucose metabolism parameters of the study group.

\begin{tabular}{|c|c|c|c|}
\hline & Banded & Non-banded & Value of $P$ \\
\hline $\mathrm{N}$ & 10 & 10 & $\mathrm{~N} / \mathrm{A}$ \\
\hline Age (years) & $35.1 \pm 10$ & $33.8 \pm 7$ & 0.7 \\
\hline \multicolumn{4}{|l|}{ Gender } \\
\hline Female & $70 \%$ & $70 \%$ & \multirow{2}{*}{1.0} \\
\hline Male & $30 \%$ & $30 \%$ & \\
\hline Initial weight (kg) & $126.3 \pm 21.6$ & $129.2 \pm 19.7$ & 0.8 \\
\hline Initial BMI $\left(\mathrm{kg} / \mathrm{m}^{2}\right)$ & $41.5 \pm 5.2$ & $40.8 \pm 4$ & 0.9 \\
\hline $\begin{array}{l}\text { Preoperative weight } \\
(\mathrm{kg})\end{array}$ & $103.9 \pm 14.8$ & $109.5 \pm 13.1$ & 0.8 \\
\hline $\begin{array}{l}\text { Preoperative BMI } \\
\left(\mathrm{kg} / \mathrm{m}^{2}\right)\end{array}$ & $37.6 \pm 2.6$ & $38.1 \pm 2.3$ & 0.6 \\
\hline $\begin{array}{l}\text { Postoperative Weight } \\
-01 \text { month }(\mathrm{kg})\end{array}$ & $93.9 \pm 14$ & $103.1 \pm 12.4$ & 0.1 \\
\hline $\begin{array}{l}\text { Postoperative BMI - } \\
01 \text { month }\left(\mathrm{kg} / \mathrm{m}^{2}\right)\end{array}$ & $33.9 \pm 2.4$ & $35.9 \pm 2.2$ & 0.07 \\
\hline $\begin{array}{l}\% \text { EWL - } 01 \text { month } \\
(\%)\end{array}$ & $29.6 \pm 5.5$ & $17.2 \pm 3.4$ & $<0.0001 *$ \\
\hline $\begin{array}{l}\% \text { BMIL - } 01 \text { month } \\
(\%)\end{array}$ & $9.7 \pm 1.1$ & $5.8 \pm 0.8$ & $<0.0001 *$ \\
\hline $\begin{array}{l}\text { Postoperative Weight } \\
-02 \text { months }(\mathrm{kg})\end{array}$ & $88.3 \pm 12.9$ & $96.8 \pm 11.2$ & 0.1 \\
\hline $\begin{array}{l}\text { Postoperative BMI - } \\
02 \text { months }\left(\mathrm{kg} / \mathrm{m}^{2}\right)\end{array}$ & $31.9 \pm 2.2$ & $33.8 \pm 2.4$ & 0.09 \\
\hline $\begin{array}{l}\% \text { EWL }-02 \text { months } \\
(\%)\end{array}$ & $46 \pm 7$ & $34.2 \pm 9$ & $0.004544 * *$ \\
\hline $\begin{array}{l}\% \text { BMIL - } 02 \text { months } \\
(\%)\end{array}$ & $15 \pm 1.4$ & $11.5 \pm 2.1$ & $0.000248 * * *$ \\
\hline $\begin{array}{l}\text { Postoperative Weight } \\
-03 \text { months }(\mathrm{kg})\end{array}$ & $84.4 \pm 12.3$ & $92.2 \pm 11.3$ & 0.2 \\
\hline $\begin{array}{l}\text { Postoperative BMI - } \\
03 \text { months }\left(\mathrm{kg} / \mathrm{m}^{2}\right)\end{array}$ & $30.5 \pm 2$ & $32.2 \pm 2.8$ & 0.2 \\
\hline $\begin{array}{l}\% \text { EWL }-03 \text { months } \\
(\%)\end{array}$ & $57.3 \pm 8$ & $47.1 \pm 14.1$ & 0.06 \\
\hline $\begin{array}{l}\% \text { BMIL - } 03 \text { months } \\
(\%)\end{array}$ & $18.8 \pm 1.8$ & $15.7 \pm 3.2$ & $0.016637 * * * *$ \\
\hline $\begin{array}{l}\text { Preoperative glucose } \\
(\mathrm{mg} / \mathrm{dL})\end{array}$ & $85.8 \pm 8$ & $86.3 \pm 7$ & 0.76418 \\
\hline $\begin{array}{l}\text { Glucose }-3 \text { months } \\
(\mathrm{mg} / \mathrm{dL})\end{array}$ & $77.8 \pm 6.9$ & $82.8 \pm 5.9$ & 0.14986 \\
\hline $\begin{array}{l}\text { Preoperative insulin } \\
(\mu \mathrm{IU} / \mathrm{mL})\end{array}$ & $14.4 \pm 4.3$ & $14.8 \pm 7.6$ & 0.72786 \\
\hline $\begin{array}{l}\text { Insulin }-3 \text { months } \\
(\mu \mathrm{IU} / \mathrm{mL})\end{array}$ & $7.6 \pm 1.9$ & $7.8 \pm 3.1$ & 0.4965 \\
\hline Preoperative HOMA & $3.1 \pm 1.1$ & $3.2 \pm 1.9$ & 0.70394 \\
\hline HOMA - 3 months & $1.5 \pm 0.4$ & $1.6 \pm 0.8$ & 0.9681 \\
\hline $\begin{array}{l}\text { Percentage of variation } \\
\text { of HOMA }(\%)\end{array}$ & $-49.1 \pm 16.9 \%$ & $-43.7 \pm 19.9 \%$ & 0.62414 \\
\hline
\end{tabular}

$\mathrm{N}$ : number of individuals; BMI: body mass index; \%EWL: percentage of excess weight loss; \%BMIL: percentage of body mass index loss; HOMA: homeostasis model assessment. Post-hoc power analysis: $* 100 \%$; ** $90.5 \%$; *** $99.2 \%$; **** $76.1 \%$. presented in TABLE 1. FIGURES 1 and 2 present graphic representations of the evolutions of $\%$ EWL and \%BMIL in both groups over time.

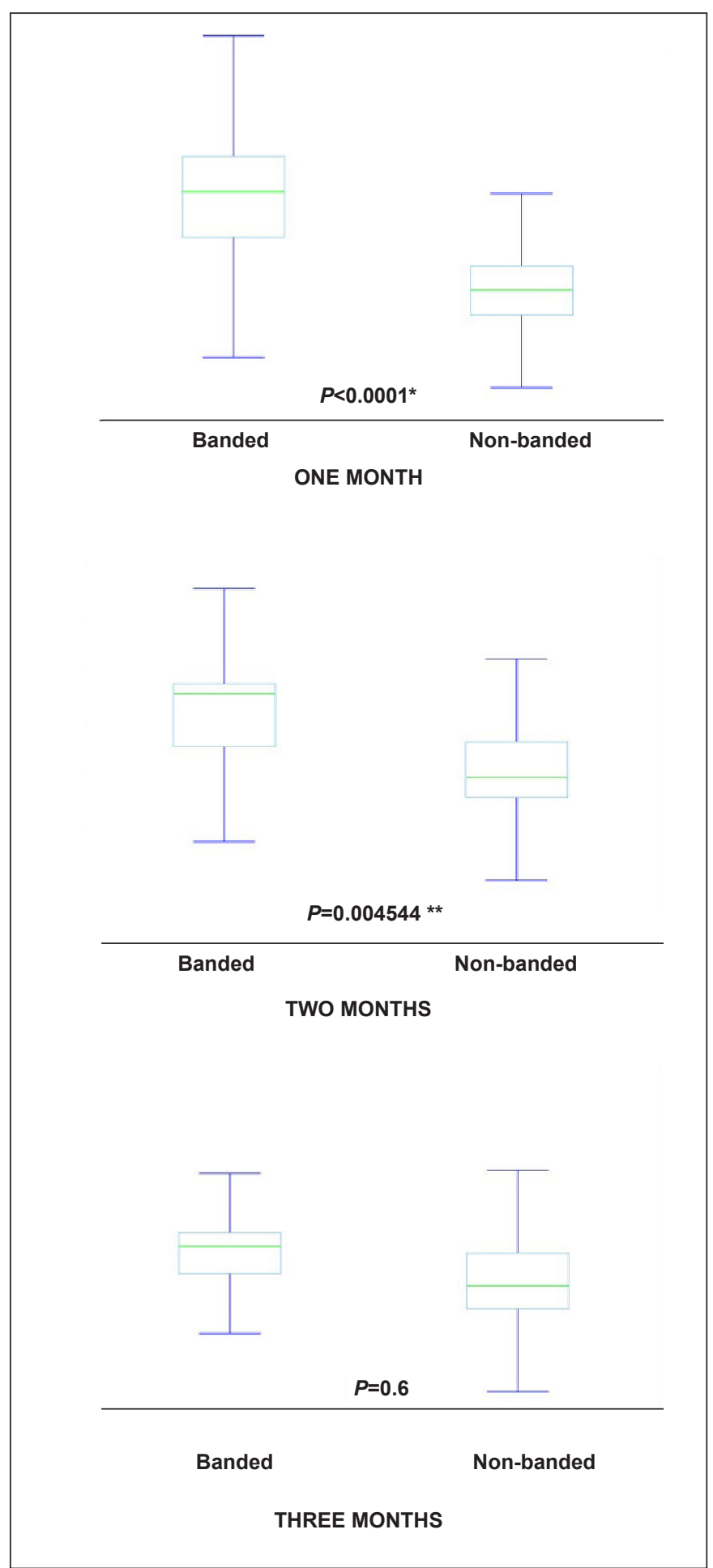

FIGURE 1. Comparison of the percentages of excess weight loss following banded versus non-banded one-anastomosis gastric bypass over a 3-month follow-up. 


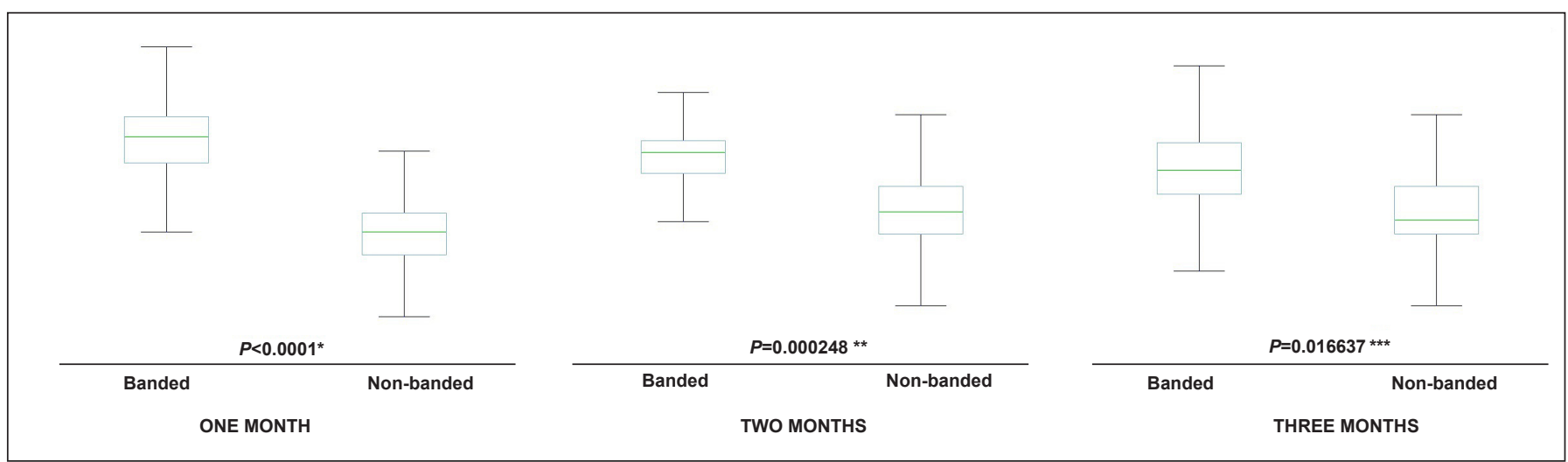

FIGURE 2. Comparison of the percentages of total body mass index loss following banded versus non-banded one-anastomosis gastric bypass over a 3-month follow-up.

At three months, banded OAGB led to significant decreases of insulin $(14.4 \pm 4.3$ vs $7.6 \pm 1.9 ; P=0.00044)$ and $\mathrm{HOMA}(3.1 \pm 1.1$ vs $1.5 \pm 0.4 ; P=0.00044)$, whereas non-banded OAGB also led to significant decreases of insulin $(14.8 \pm 7.6$ vs $7.8 \pm 3.1 ; P=0.006)$ and HOMA (3.2 \pm 1.9 vs $1.6 \pm 0.8 ; P=.0041)$. Glucose levels were not significantly affected by both banded $(P=0.06)$ and non-banded
OAGB $(P=0.3)$.(FIGURE 3$)$ The percentages of variation of HOMA over the 3-month follow-up did not differ between banded and non-banded OAGB $(-49.1 \pm 16.9 \%$ vs $-43.7 \pm 19.9 \% ; P=0.62414)$. (TABLE 1). The variation of HOMA was not significantly correlated with both $\%$ EWL and $\%$ BMIL within both groups, and also among the overall population. (TABLE 2).

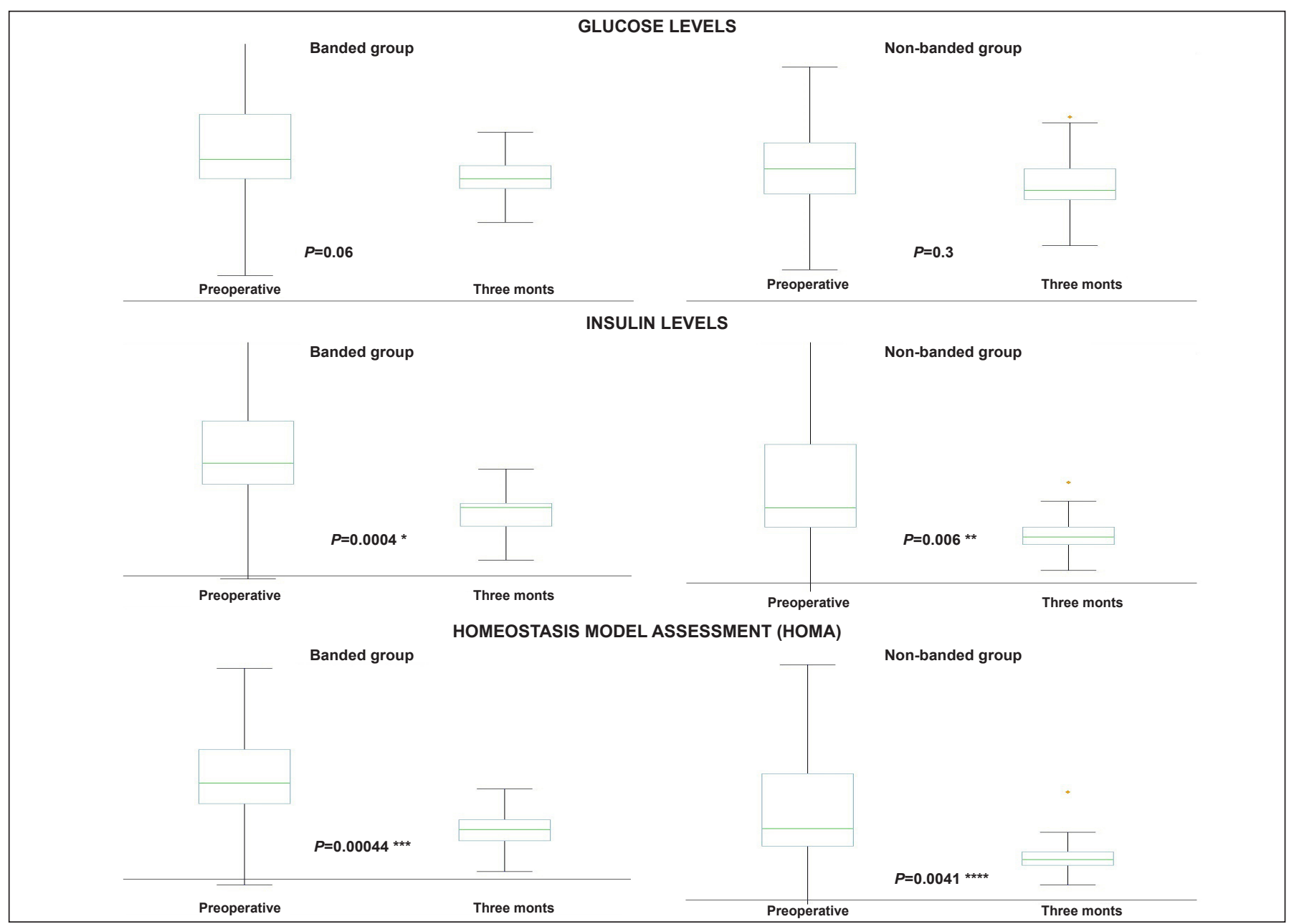

FIGURE 3. Evolution of glucose metabolism parameters after banded versus non-banded OAGB over a 3-month follow-up. 
TABLE 2. Correlations between the percentages of variation of HOMA and the weight loss outcomes after one anastomosis gastric bypass.

\begin{tabular}{lcc}
\hline & $\begin{array}{c}\text { Correlation } \\
\text { Coefficient (R) }\end{array}$ & Value of $\boldsymbol{P}$ \\
\hline $\begin{array}{l}\text { Variation of HOMA vs \%EWL } \\
\text { (Banded group) }\end{array}$ & -0.30909 & 0.38484 \\
$\begin{array}{l}\text { Variation of HOMA vs \%BMIL } \\
\text { (Banded group) }\end{array}$ & -0.0304 & 0.93357 \\
$\begin{array}{l}\text { Variation of HOMA vs \%EWL } \\
\text { (Non-banded group) }\end{array}$ & 0.21212 & 0.55631 \\
$\begin{array}{l}\text { Variation of HOMA vs \%BMIL } \\
\text { (Non-banded group) }\end{array}$ & 0.32827 & 0.35442 \\
$\begin{array}{l}\text { Variation of HOMA vs \%EWL } \\
\text { (Overall group) }\end{array}$ & -0.00902 & 0.96988 \\
$\begin{array}{l}\text { Variation of HOMA vs \%BMIL } \\
\text { (Overall group) }\end{array}$ & 0.05342 & 0.82299 \\
\hline $\begin{array}{l}\text { \%EWL: percentage of excess weight loss; \%BMIL: percentage of body mass index loss; HOMA: } \\
\text { homeostasis model assessment. }\end{array}$ & DISCUSSION &
\end{tabular}

The current study observed that banded OAGB led to significantly higher early weight loss than the standard technique. However, it was also possible to observe that the statistical significance of this finding decreased over the short 3-month follow-up. Whether this higher weight loss may be attributable to the difficult early adaptation to a restrictive band around the pouch or may be a sustained achievement over a longer follow-up remains to be determined.

There is no consensus regarding the influence of the use of a silicone ring or not on weight loss outcomes. A prospective 10-year study by Magro et al. reported a $\%$ EWL of $79.7 \%$ and a $\%$ BMIL of $30.8 \%$ among individuals with morbid obesity following banded $\mathrm{RYGB}^{(18)}$. Heneghan et al. have reported a better weight loss after banding RYGB, especially among individuals with super obesity, and also a low band-related morbidity ${ }^{(8)}$. On the other hand, Lemmens has not observed differences in early weight loss, although the individuals who underwent banded RYGB presented a better weight loss and less weight regain at a 5 -year follow-up ${ }^{(9)}$. A systematic review conducted by Mahawar et al. concluded that primary banded RYGB patients do have a superior weight loss outcome in the long-term, but this advantage comes with a definite band-related complication rate, which agrees with the results of a meta-analysis performed by Buchwald et al., which stated that banded gastric bypass appears to result in sustained weight loss and likely greater than that achieved by standard RYGB ${ }^{(19,20)}$. There is also evidence pointing out that food intolerance increases over time after banded RYGB, which may influence the late weight loss outcomes ${ }^{(21)}$.

Furthermore, our results point out that there is an early powerful metabolic response after OAGB, regardless of the use of a band or apparently detached from the weight loss outcomes, since the improvement of insulin resistance was independent of the excess and percent weight loss. Celik et al. ${ }^{(22)}$ have previously reported the achievement of glycemic control one month after OAGB, and Taha et al. ${ }^{(23)}$ observed remission of diabetes in $84 \%$ of individuals which underwent OAGB. The findings of the current study reinforce this strong metabolic response following OAGB and also signals that, as early as mere three months, these metabolic outcomes seem to be more linked to structural changes in intestinal transit than to weight loss itself. Since the current study enrolled non-diabetic individuals, the significant decrease of insulin resistance demonstrated should be expected to preclude the development of diabetes among highrisk pre-diabetic populations.

In regard to the safety profile of laparoscopic OAGB, according to the currently available evidence, there are acceptable early and late complication rates, and the frequency of symptomatic bile reflux is lower than firstly feared, although this information mainly relies on self-reporting ${ }^{(7,24-26)}$.

Nonetheless, the evidence on the use of bands in individuals who undergo OAGB remains more inconclusive. The first study that investigated this adaptation of the original technique was published by Clarke et al., which reported an excellent 5-year \%EWL of $89 \%$, associated with food intolerance/vomiting, bile reflux and marginal ulcer in $18.6,10.3$ and $7.7 \%$ of patients, respectively ${ }^{(10)}$. Sheikh et al. published years later a continuation of this study and reported a mean 11 -year $\%$ EWL of $84.3 \% ; 9.4 \%$ of the patients required conversion to RYGB due to bile reflux ${ }^{(11)}$.

The main limitations of the present study are its short follow-up time and small sample. Although they were sufficient to determine the early outcomes and safety profile, it precludes ultimate largescale conclusions, as well as does not permit inferences in regard to long-term band or alkaline reflux-related complications. To date, there is limited evidence on potential harmful effects of OAGB on gastric carcinogenesis. A review performed by Scozzari et al. reported 33 cases of gastroesophageal cancers after bariatric surgery ${ }^{(27)}$. Among them, four cases of gastric cancers were reported after surgery using the "loop gastric bypass" technique, an "ancestor" of the OAGB. Three cases were found in the excluded stomach, an as such, are not related to bile acid reflux to the gastric pouch, and one case was a gastric stump carcinoma which occurred 26 years after surgery ${ }^{(28,29)}$. After OAGB, there was a single case of gastric cancer published in the literature which also developed on the excluded stomach, occurring 9 years after surgery ${ }^{(30)}$. On the other hand, to specifically evaluate the influence of the band on the studied early outcomes, its prospective randomized design was appropriate. A blinded study should be better suited, however it would pose a significant ethical issue, since there is a well-established band-related morbidity for this procedure. Hence, a cautious and careful clinical follow-up of the studied patients is mandatory, as well as the presentation of later results. The exclusion of individuals with diabetes and/or impaired glucose tolerance also avoided to evaluate the influence of this procedure among populations with severe insulin resistance, but it was necessary to decrease the possibility of heterogeneity within such a small sample. Nonetheless, the powerful early metabolic effect of OAGB observed in this study, regardless of band use or even weight loss, emphasizes the great potential benefits of this procedure to improve insulin sensitivity.

\section{CONCLUSION}

Banded OAGB led to a significantly higher weight loss than the standard technique over a 3-month follow-up. Both banded and non-banded OAGB led to a significant early improvement of insulin resistance regardless of weight loss, demonstrating the strong metabolic outcomes of OAGB.

\section{Statement of informed consent}

Informed consent was obtained from all individual participants included in the study. 


\section{Statement of human and animal rights}

All procedures performed in studies involving human participants were in accordance with the ethical standards of the institutional and/or national research committee and with the 1964 Helsinki declaration and its later amendments or comparable ethical standards.

\section{Authors' contribution}

Cazzo E designed the study, performed the statistical analysis, took part in the surgical proceedings and wrote the article. Valerini FG and Chaim FHM collected the data. Soares PFC performed the literature review. Ramos AC and Chaim EA performed the surgical proceedings.

\section{Orcid}

Everton Cazzo. Orcid: 0000-0002-5804-1580.

Felipe Gilberto Valerini. Orcid: 0000-0002-4219-761X.

Fábio Henrique Mendonça Chaim. Orcid: 0000-0003-2603-6805.

Pedro França da Costa Soares. Orcid: 0000-0001-7541-7431.

Almino Cardoso Ramos. Orcid: 0000-0001-6805-1750.

Elinton Adami Chaim. Orcid: 0000-0001-9370-9518.

Cazzo E, Valerini FG, Chaim FHM, Soares PFC, Ramos AC, Chaim EA. Efeitos precoces do bypass gástrico de anastomose única com e sem anel sobre a perda de peso e o metabolismo glicêmico: um estudo prospectivo randomizado. Arq Gastroenterol. 2019;56(1):15-21.

RESUMO - Contexto - A influência da colocação de bandas sobre os resultados do bypass gástrico de anastomose única (BGAU) não foi profundamente estudada. Objetivo - Comparar a perda precoce de peso e os parâmetros do metabolismo da glicose após bypass gástrico de anastomose única (BGAU) com e sem anel. Métodos - Estudo prospectivo randomizado que avaliou 20 obesos mórbidos submetidos ao BGAU com e sem anel e acompanhados por três meses. A perda de peso (percentual de perda do excesso de peso - \% PEP e percentual de perda de peso - \%PP) e parâmetros do metabolismo da glicose (glicemia, insulina e modelo homeostático de avaliação - HOMA) foram comparados. Resultados - O grupo com anel apresentou \%PEP significativamente maior em um mês $(29,6 \pm 5,5 \%$ vs $17,2 \pm 3,4 \% ; P<0,0001)$ e dois meses após a cirurgia $(46 \pm 7 \%$ vs $34,2 \pm 9 \% ; P=0,004544)$, bem como \%PP significativamente maior em um mês $(9,7 \pm 1,1 \%$ vs $5,8 \pm 0,8 \% ; P<0,0001)$, dois meses $(15 \pm 1,4 \%$ vs $11,5 \pm 2,1 ; P=0,000248)$ e três meses $(18,8 \pm 1,8 \%$ vs $15,7 \pm 3,2 \% ; P=0,016637)$. Aos três meses, o BGAU com anel resultou em reduções significativas de insulina $(14,4 \pm 4,3$ vs $7,6 \pm 1,9 ; P=0,00044)$ e HOMA ( $3,1 \pm 1,1$ vs $1,5 \pm 0,4 ; P=0,00044)$, enquanto o BGAU sem anel também levou a reduções significativas de insulina (14,8 $\pm 7,6$ vs $7,8 \pm 3,1$; $P=0,006)$ e HOMA $(3,2 \pm 1,9$ vs $1,6 \pm 0,8 ; P=0,0041)$. A variação percentual de HOMA não diferiu significativamente entre BGAU com bandas ou sem anel $(P=0,62414)$; no geral, a variação percentual do HOMA não foi correlacionada com \%PEP $(P=0,96988)$ ou \%PP $(P=0,82299)$. Conclusão - O BGAU com anel levou a uma maior perda de peso precoce do que a técnica padrão. O BGAU com ou sem anel levou à melhora precoce na resistência à insulina, independentemente da perda de peso.

DESCRITORES - Cirurgia bariátrica. Derivação gástrica. Obesidade. Perda de peso. Resistência à insulina.

\section{REFERENCES}

1. Mahawar KK, Kumar P, Carr WR, Jennings N, Schroeder N, Balupuri S, Small PK. Current status of mini-gastric bypass. J Minim Access Surg. 2016;12:305-10.

2. Rutledge R. The mini-gastric bypass: experience with the first 1,274 cases. Obes Surg 2001;11:276-80.

3. Chevallier JM, Arman GA, Guenzi M, Rau C, Bruzzi M, Beaupel N, et al. One thousand single anastomosis (omega loop) gastric bypasses to treat morbid obesity in a 7-year period: outcomes show few complications and good efficacy. Obes Surg. 2015;25:951-8.

4. Lee WJ, Lin YH. Single-anastomosis gastric bypass (SAGB): appraisal of clinical evidence. Obes Surg. 2014;24:1749-56.

5. Lee WJ, Ser KH, Lee YC et al.: Laparoscopic Roux-en-Y vs. Minigastric bypass for the treatment of morbid obesity: A 10-year experience. Obes Surg. 2012;22:1827-34

6. Angrisani L, Santonicola A, Iovino P, Vitiello A, Zundel N, Buchwald H, Scopinaro N. Bariatric Surgery and Endoluminal Procedures: IFSO Worldwide Survey 2014. Obes Surg. 2017;27:2279-89.

7. De Luca M, Tie T, Ooi G, Higa K, Himpens J, Carbajo MA, et al. Mini Gastric Bypass-One Anastomosis Gastric Bypass (MGB-OAGB)-IFSO Position Statement. Obes Surg. 2018;28:1188-206.

8. Heneghan HM, Annaberdyev S, Eldar S, Rogula T, Brethauer S, Schauer P. Banded Roux-en-Y gastric bypass for the treatment of morbid obesity. Surg Obes Relat Dis. 2014;10:210-6.

9. Lemmens L. Banded Gastric Bypass: Better Long-Term Results? A Cohort Study with Minimum 5-Year Follow-Up. Obes Surg. 2017;27:864-72.

10. Clarke MG, Wong K, Pearless L, Booth M. Laparoscopic silastic ring mini-gastric bypass: a single centre experience. Obes Surg. 2013;23:1852-7.

11. Sheikh L, Pearless LA, Booth MW. Laparoscopic Silastic Ring Mini-Gastric Bypass (SR-MGBP): Up to 11-Year Results from a Single Centre. Obes Surg. 2017;27:2229-34.
12. García-Caballero M, Valle M, Martínez-Moreno JM, Miralles F, Toval JA, Mata $\mathrm{JM}$, et al. Resolution of diabetes mellitus and metabolic syndrome in normal weight 24-29 BMI patients with One Anastomosis Gastric Bypass. Nutr Hosp. 2012;27:623-31

13. Zubiaga L, Abad R, Ruiz-Tovar J, Enriquez P, Vílchez JA, Calzada M, et al The Effects of One-Anastomosis Gastric Bypass on Glucose Metabolism in Goto-Kakizaki Rats. Obes Surg. 2016;26:2622-8.

14. Matthews DR, Hosker JP, Rudenski AS, Naylor BA, Treacher DF, Turner RC. Homeostasis model assessment: insulin resistance and beta-cell function from fasting plasma glucose and insulin concentrations in man. Diabetologia. $1985 ; 28: 412-9$

15. National Institutes of Health. Gastrointestinal surgery for severe obesity: National Institutes of Health Consensus Development Conference statement. Am J Clin Nutr 1992;55(2 Suppl):615S-619S.

16. Chaim EA, Pareja JC, Gestic MA, Utrini MP, Cazzo E. Preoperative multidisciplinary program for bariatric surgery: a proposal for the Brazilian Public Health System. Arq Gastroenterol. 2017;54:70-4.

17. Chaim EA, Ramos AC, Cazzo E. Mini-gastric bypass: description of the technique and preliminary results. Arq Bras Cir Dig. 2017;30:264-6.

18. Magro DO, Ueno M, Coelho-Neto JS, Callejas-Neto F, Pareja JC, Cazzo E. Long-term weight loss outcomes after banded Roux-en-Y gastric bypass: a prospective 10-year follow-up study. Surg Obes Relat Dis. 2018;14:910-7.

19. Mahawar KK, Parikh C, Carr WR, Jennings N, Balupuri S, Small PK. Primary banded Roux-en-Y gastric bypass: a systematic review. Obes Surg. 2014;24 1771-92.

20. Buchwald H, Buchwald JN, McGlennon TW. Systematic review and meta-analysis of medium-term outcomes after banded Roux-en-Y gastric bypass. Obes Surg. 2014;24:1536-51. 
21. Gobato RC, Cazzo E, Baltieri L, Modena DAO, Chaim EA. Food Intolerance 1 Year After Banded Roux-En-Y Gastric Bypass. Obes Surg. 2018;29:485-91.

22. Celik A, Pouwels S, Karaca FC, Çağlltay E, Ugale S, Etikan İ, et al. Time to Glycemic Control - an Observational Study of 3 Different Operations. Obes Surg. 2017:27:694-702.

23. Taha O, Abdelaal M, Abozeid M, Askalany A, Alaa M. Outcomes of One Anastomosis Gastric Bypass in 472 Diabetic Patients. Obes Surg. 2017;27:2802-10.

24. Carbajo MA, Fong-Hirales A, Luque-de-León E, Molina-Lopez JF, Ortiz-de-Solórzano J. Weight loss and improvement of lipid profiles in morbidly obese patients after laparoscopic one-anastomosis gastric bypass: 2-year follow-up. Surg Endosc. 2017;31:416-21.

25. Lessing Y, Pencovich N, Khatib M, Meron-Eldar S, Koriansky J, Abu-Abeid S. One-anastomosis gastric bypass: first 407 patients in 1 year. Obes Surg. 2017;27:2583-9.
26. Musella M, Susa A, Manno E, De Luca M, Greco F, Raffaelli M, et al. Complications following the mini/one anastomosis gastric bypass (MGB/OAGB): a multi-institutional survey on 2678 patients with a mid-term (5 years) follow-up. Obes Surg. 2017;27:2956-67.

27. Scozzari G, Trapani R, Toppino M, Morino M. Esophagogastric cancer after bariatric surgery: systematic review of the literature. Surg Obes Relat Dis. 2013;9:133-42.

28. Guirat A, Addossari HM. One Anastomosis Gastric Bypass and Risk of Cancer. Obes Surg. 2018;28:1441-4.

29. Babor R, Booth M. Adenocarcinoma of the gastric pouch 26 years after loop gastric bypass. Obes Surg. 2006;16:935-8.

30. Wu CC, Lee WJ, Ser KH, Chen JC, Tsou JJ, Chen SC, Kuan WS. Gastric cancer after mini-gastric bypass surgery: a case report and literature review: gastric cancer after mini-gastric bypass. Asian J Endosc Surg. 2013;6:303-6. 